\title{
The Customer Experience in the Era of Electronic Service Offering
}

\author{
Wiem Jenzri Sfar
}

Faculty of Economics and Management in Sfax - Tunisia

\begin{abstract}
This paper analyzes how the customer experience could be impacted by the integration of electronic supply service, as a complementary channel of distribution. Far from trivial, the induced changes generate a restructuring of the contents of the service experience whose impact on perceived quality and service brand image should be seriously considered by the provider.
\end{abstract}

Keywords: Electronic offer, experience, service, content of experience.

\section{Introduction}

The growing scale of the status of the service sector in global economy, boosted in part by the popularization of Internet technology, encourages researchers and practitioners to study the impacts of the integration of electronic sales medium on business practices in marketing services, on the one hand, and on the behavior and perceptions of consumers, on the other. Indeed, managers incorporate this type of support as part of a multi-channel distribution strategy which is, at the same time, a sale point and an additional point of contact with the customer. The latter, on his part, finds himself in a context of offer different from the usual one leading - among others - to a service experience different from the traditional experience of reference that some authors call the passage from a marketplace to a market space (Rayport and Sviokla, 1995). Regarding the service provider, this passage requires that the parallel between the decision to integrate the electronic support of service delivery and the mastery of its impact on the client be fully established; failing this the accessibility offered to the client will be detrimental to the quality and the way the service experience is lived. Besides, the latter is an integral part of the consumer perception concerning the quality of service delivered and the formation of the brand image in his mind (Camelis and Llosa, 2009).

Henceforth, the focus of this paper is to show in an analytical way how the service experience of the consumer happens to be influenced by the change in the context of service provision. From this perspective, our initial hypothesis is that the transition to the purchase and / or consumption in the context of electronic sales deeply alters and at different levels the experience that follows. A theoretical framework of the concept of service experience will, then, be exposed, in a first part, and an analysis of the impact of change in supply on the latter and its managerial implications will be determined, in a second part.

\section{Service Experience: Conceptual Framework}

\section{Definition of the Service Experience}

The notion of experience has been intimately associated, at a very early stage, with that service delivery, thus, leading to the emergence of the concept of service experience. This phenomenon has raised simultaneously the interest, on the one hand, of academics, thanks to its conceptual

Copyright (C) 2012 Wiem Jenzri Sfar. This is an open access article distributed under the Creative Commons Attribution License unported 3.0, which permits unrestricted use, distribution, and reproduction in any medium, provided that original work is properly cited. Contact author: Wiem Jenzri Sfar E-mail: jenz.wiem@gmail.com 
perspectives and, on the other hand, professionals because of its consequent impact on profitability through increased customer load in the servuction process. Since the work of Eiglier and Langeard (1987), the service experience has often been the focus of debate but few studies have been interested in a comprehensive manner and from the consumer's side. Camelis and Llosa (2009) propose a definition that seems the clearest and most accurate while standing from the point of view of consumers', the service experience can be defined as "the perception of all the tasks performed and interactions experienced in contact with elements of servuction system during the time spent in the company". This is an angle overshadowing an experiential vision that regards the consumer as an individual living a unique experience, thus, going beyond the simple fact to consider him as a human element involved in the process of servuction.

In addition, the consumer draws his knowledge on the service brand from his personal experience during the various contacts with it (Berry, 2000). However, this contact may be of various types giving rise to two types of experience: the direct experience and indirect experience.

The indirect experience is the experiential background of the customer with the brand without having direct contact with the service (purchase or consumption). This type of experience includes communications on the service brand, all media platforms combined, word of mouth on the brand and all information transmitted by the press about it. It is then for the client, information sources controlled by the service provider such as advertising and other uncontrolled sources like consumer magazines.

As for direct experience, it is the experiential background of purchase or consumption of the service marked throughout the direct relationship between the client and the service brand. Moreover, the success of this experience depends partly on the client himself to the extent that the achievement of the service requires the participation of the latter according to a servuction system more or less engaging for the customer. Furthermore, the role of direct experience of service is crucial because it is the main source of knowledge of the brand by the customer and the sense that he appropriates to it (Berry, 2000).

\section{Contents of the Service Experience}

Aside from the contributions of psychology (Bouchet, 2004) and experiential marketing (Fornerino et al., 2005) dealing with notions of customer participation and service encounter, the content of the service experience has been studied, recently, in a more global consumption approach. The main finding is that "any service experience is conceived by the consumer as the actual experience of a succession of permanent interdependent experiential activities, of different types and reflect the interactions that the consumer develops with the physical environment and human service needed to the achievement of service" (Camelis and Llosa, 2009). Thus, a structure of the service experience turning around five different types of activities has been proposed by Camelis and Llosa (2009):

\section{The Behavioral Activities}

They refer to the physical role that amounts to the customer during the experience period and according to the servuction system available. The latter makes a partial transfer, more or less important, of the work of staff to the customer leading, essentially, to physical actions such as moving the client (driving, walking etc.) and the objects (push, test etc.).

\section{The Cognitive Activities}

These activities represent the mental effort by the customer (reflection, reasoning, thought) during the experience. It is mainly related to the management of participation (time, route, direction), choice, decision making (needs assessment, comparisons of alternatives) and optimization of experience (understanding of supply and environment). 


\section{The Emotional Activities}

These are the different emotions that consumers may have during the experience period. They are obviously either positive and pleasant as the feeling of joy, contentment and surprise or negative and unpleasant as embarrassment, anger, disgust and impatience.

\section{The Perceptual and Sensory Activities}

As their name suggests, these activities involve the five sensory systems of an individual (sight, smell, taste, hearing, touch). They are stimulated by material and / or human environmental elements and make up most of the reactions felt towards the latter. Besides, sensations such as oppression, hunger and fatigue may be part of this category of activities and may complete it.

\section{The Relational and Social Activities}

This is all the interactions that occur during the period of experience in which the counterpart is human. They are oriented toward the contact staff or the attending customers. These interactions can be verbal, nonverbal or even behavioral (observation, imitation, listening to discussions, comparisons etc...).

\section{Impact of Electronic Service Offering on Customer Experience}

We rely on identifying the impact levels and their analysis on the classification of activities that comprise the content of the experience as it was presented previously. Moreover, these activities represent the way the service experience has been lived by the customer, which is no other thing but the experiential intensity felt.

\section{Impact on the Level of Behavioral Activities}

The client is conventionally considered as a major player in the service, whatever the context, his participation is essential to the achievement of the service. However, this participation varies with the servuction system involved and therefore with the context of supply mentioned. Thus, in a traditional and strictly behavioral perspective, this participation is reflected in the physical movement of the customer and further work on moving objects or documents needed to be supported, later, by the employee (Camelis and Llosa, 2009); This can be seen as a joint service delivery in a co-servuction system in which the client and staff are both parties. Again, in a behavioral perspective, the employee should assist and guide customers in the physical actions required optimizing their participation and, consequently, reaching a better service experience.

By cons, in the framework of an electronic supply, the service is offered online via a website providing an absolute accessibility and allowing operators to cross traditional physical and geographical boundaries including the customer's physical actions. Indeed, provided that the latter has a home Internet connection, his physical role comes to an end in a virtually integral way to be reduced to putting the computer on and making a few clicks. Consequently, the co-delivery service shared between the service provider and the client gives way to self-provision of service where the customer is almost the only actor (attended by a multimedia interface) causing thus an electronic service experience much less restrictive in terms of the customer's physical role and, therefore, behavioral activities but possibly entailing constraints of a different nature. Indeed, the context of electronic bid could disrupt the smooth running of the service if a low level of expertise of the client's Internet support is accompanied by fairly complex needs.

In summary, in the field of behavioral activities, the transition from the context of traditional service offering to the electronic one favours a service experience marked by comfort and increased accessibility to the service by minimizing or even eliminating the physical role of the consumer at the cost of technical constraints that may possibly ensue.

\section{Impact on the Level of Cognitive Activities}

The cognitive activities provided by the consumer are directly affected by the 
context of electronic offer and especially the function of interactivity of the website service. This concept is closely related to the supply line and reflects "the degree to which the users of a medium can influence the form or content of a digital environment in real time," or, "the possibility for the consumer to modify the environment which is transmitted to him" (Steuer, 1992).

When it comes to electronic environment, the level of interactivity is found to be variable, unlike the traditional context. Indeed, the degree of control of information requested in the consumer varies with the website multimedia system used; some systems are more interactive than others and therefore involve a degree of control of information by the consumer higher than others. Furthermore, interactivity refers to a degree of information control in terms of communication (indirect experience) mostly (Ariely, 2000). Thus, traditional communication characterized by the passivity of the consumer when he's submitted to the information and the linearity of the latter are disrupted by the electronic environment for the benefit of interactive communication where the consumer goes through the information and acts in a dynamic way depending on the degree of control of information at his disposal.

In another aspect, the operation of evaluation and comparison of the alternatives carried out by the consumer and which is an integral part of prepurchase cognitive activities is affected by the change of the context of service provision. Thus, in a traditional context, the consumer mobilizes cognitive resources to sort, evaluate and compare alternative supply to finally make a choice and generally does not have the freedom of choice of information content. Moreover, the uneven information needs are faced with a constant and often inappropriate level of information available in a traditional shopping environment. Therefore, the consumer is faced with a large volume of information that does not necessarily meet his need but which exceeds his processing capacity and it is at this level that heuristics interfere to facilitate the formation of preferences .On the other hand, when it comes to the electronic context, information processing is systematized through the interactive tools of this technology and which support the selection, the sorting and the information comparison as part of the mental effort traditionally made by the customer. Under these conditions, the most central criteria of the consumer choice are more distinct and his preferences are clearer after the comparison of service offering alternatives (Volle, 2000). Consequently, the electronic environment allows consumers to carry out the data processing in a more rational way leading to a more reliable final choice compared to the traditional context in which this processing, exclusively mobilizing cognitive abilities, proves rather heuristic and, in some cases, can even be emotional.

\section{Impact on the Level of Emotional Activities}

The environment of the sale and distribution of electronic services promotes a particular emotional state to the customer. This finding has interested many researchers who agree that a phenomenon of immersion occurs when browsing the Internet (Fornerino, HelmeGuizon and Gotteland, 2006, 2008). At this level, the notion of interactivity as it was defined previously is involved because it promotes the fact that the cybershopper happens to be immersed in a virtual digital environment. Indeed, the electronic medium offers a degree of interactivity that offers the consumer the freedom of choice of message construction based on hypertext links and interactive tools available. This promotes a state of loss of sense of time and reality as well as a large concentration together with a strong level of commitment in the virtual digital environment, which are nothing but outward signs of the immersive state that the cybershopper can go through. We present this phenomenon as "a condition that occurs during the browsing stage, characterized by an uninterrupted sequence facilitated by the intrinsically 
enjoyable machine interactivity, accompanied by a loss of self-awareness and a gain of self-strengthening" (Hoffman and Novak, 1996).

The state of the immersion experienced by the cybershopper is somehow pleasant. Moreover, some benefits are associated with it and prove to be of different nature: the benefits of experiential, hedonistic and other utilitarian ones in nature (and Gurviez Montety, 2001). Indeed, the experiential and hedonistic benefits are favored mainly by the absence of geographical constraints and speed of real time which reflects the experiential aspect (Holbrook and Hirschman, 1982), whereas the utilitarian advantages refer to the idea that buying online is a behavior directed toward a specific search and therefore to a specific purpose (Gurviez and Montety, 2001). In purpose, we assume that the context of electronic service offering promotes a state of loss of oneself that drives the consumer in an enjoyable immersive experience specific to the virtual and digital world that he/she himself/herself shapes and undergoes the same time.

\section{Impact on the Level of Sensory Activities}

From the outset, we recognize that the service offering in an electronic environment significantly reduces sensory activities because of the dematerialization and the virtuality of the space of the offer. Indeed, the electronic environment offers a virtual environment where digital information is the only form that can take the service and its environment and thus substitutes the components and material and physical flows for other virtual digital ones having as the only medium a single electronic interface representing the service website. Under these conditions, sensory activities are reduced from five to two sensory systems, sight and hearing. Henceforth, we reject the sense of touch though it is essential to make a purchase online (clicking, typing on the keyboard etc...). This rejection is justified by the fact that this sense is not affected by environmental stimuli in an electronic context, as is the case of sight and hearing.
Furthermore, when it comes to online service offering, the framework of the experience is limited to a virtual retail space via an interface of a website where design and style graphics as well as audio tools (possibly background music) are the only environmental stimuli - exclusively digital - sensory activities. Therefore, for the consumer, the service experience is now lived in a virtual atmosphere of sales space where the wealth of presentation lies only in the formal features of the website service (colors, images, graphics, animation, video, music).In addition, we should bear in mind that the client is already accustomed to an atmosphere of service offering space in a traditional and physical setting and may constitute a reference. So, the service provider should avoid creating a "gap" between the ordinary reference framework and that of the new one (service website) to maintain the same level of familiarity for the client even with a change of the offer framework.

In short, with the transition to an environment of electronic offer, the service experience is less stimulated because of the restriction of sensory activities which is generated, in turn, by the abolition of physical and human environmental stimuli now invalid in an atmosphere of virtual sales.

\section{Impact on the Level of Social Activities}

The social activities of a service experience are influenced by the changing context of the offer on two levels: interactions with staff and those with other customers. It should be noted that in a traditional context, a better relationship between client and staff generates a better service experience; hence, the predominant role of employees in achieving this goal providing thus a human and customized footprint, that permeates the service experience. On the other hand, when it comes to electronic environment, the human dimension with the benefits that follow is totally disabled in a technologically mediated relationship. At this level, the very nature of the service experience is affected: The customer moves from an experience where the main counterpart is an employee to an 
experience where he/she is confronted with a machine. Consequently, the service relationship between the client and the service provider suffers a dehumanizing effect because of the substitution of human interaction with a human-computer interaction (Philippe, 1994). Such dehumanization disrupts or even cancels empathy (which involves the consideration and the individualized attention paid by the employee to each client) and the insurance (which refers to the courtesy and helpfulness of the employee and his ability to inspire confidence) traditionally resulting from interactions between the customer and the employee in contact (Parasuraman et al., 2005).

Moreover, the quality of interactivity of the website and the degree of personalized electronic service ensuring the adaptability of responses may partially make up for the empathy and assurance of the human in the context of online offering (Barnes and Vidgen, 2003). Thus, the transition from human service experience to a technologically mediated experience is marked by the replacement of humans by an electronic interface and, consequently, the switching from human phenomena to digital phenomena: the empathy and assurance of humans being replaced by the quality of interactivity and personalization of the website interface. These last two elements reflect the possibility for the client to shape the service that best suits their needs and change the content and the form of the mediated environment in real time. However, the interpretation function of the need provided by the staff and the generally pleasant human contact can not be offset by technology despite the contribution of IT specialists in terms of electronic and interactive agent acting on behalf of an individual.

At another level, social activities are affected by the electronic environment, that of the interactions with other customers. In an environment of traditional service, two contradictory ways of perceiving the presence of other customers are possible: One the one hand, this presence can be regarded as a source of unease and discomfort due to the congestion and increased wickets wait time. On the other hand, it can be reassuring and seen as a source of shared experience and business success. Contrary to some expectations, the transposition of the social dimension to the context of electronic service proves to be possible thanks to the interactivity between online consumers through the "virtual community" function that can be offered by the service on its website (Wolfinbarger and Gilly, 2000). From then on, the discomfort caused by the mass of customers that could be present in a traditional context or even the merits of discussions with other clients can be found in an electronic environment. Thus, the cybershoppers may check the opinions and criticisms of other customers on the service in question and interact with them via a virtual community. In some cases, this social dimension is a fundamental expectation for online shoppers who improve the quality of the service experience once satisfied.

Eventually, the service experience undergoes dehumanization when technologically mediated due to the substitution of the interaction man / man by that of man / machine. However, this does not imply the cancellation of the whole social activity. In fact, interactions between clients and even between client and service provider, if necessary, are maintained insofar as the latter offers on the service website the "virtual community" function where customers can discuss and seek advice and past experiences of each other.

\section{Managerial Implications}

The incompatibility of many service websites with the expectations of ecustomers (Sabadie and Vernette, 2003) is an indicator of lack of control of a large number of the service providers in terms of issues and consequences related to the integration of the electronic distribution channel in the range of supply and, particularly, in terms of effects on the service experience in this new offering environment: it is in this context that the managerial contributions lie within the 
scope of this analytical work. In fact, understanding the changes in the characteristics of the service experience felt by the consumer and conditioned by the distribution via the electronic channel is a prerequisite for optimizing the quality of electronic service perceived by the customer (Rolland, 2005) (1), on the one hand, and forming a positive brand image of service even with the change of the sales support (Camelis and Llosa, 2009) (2), on the other hand.

Let us start with the first component on the perception of the electronic service quality by the customer. We rely on the fact that a better service experience promotes greater perceived quality of that service because the customer uses in the basis of his judgment about the quality of service elements referring to the direct experience (Bressolles, 2006). The latter are, in fact, part of most scales measuring the perceived quality of service offered either in the traditional context (eg ServQual) or the electronic (eg WebQual, NetQual). As far as the manager is concerned, two crucial implications are noteworthy: First, the service experience that the provider offers via the website is partly decisive for the quality of service that the customer will receive. Second, in holding that the client is already accustomed to a service experience and a level of perceived quality more or less constant in a traditional context, the change of the latter leads to changes in the service experience which generat, in their turn, changes in the level of perceived quality of reference: This is, for the manager, a problem of standardization of the level of perceived quality of service under the pressure of the heterogeneity of the real life experiences (because of the change in the context of purchase and / or consumption of the service). We therefore advocate to consider this problem from the standardization of quality of the service experience itself whatever the context of the offer, which can not be achieved without understanding the alterations made by the change of this environment and the control of its impact on the client. In practice, the manager should fill the dehumanization of the relationship of eservice, on the one hand, by the provision of a degree of customization of the website which entitles customers to a freedom of adaptation of content meeting very heterogeneous needs in terms of nature and intelligibility, and on the other hand, by the continuity of remote contact through the possibility for the customer to get in touch with the provider via the website and the satisfactory reactivity of the latter with regard to the customer's requests.

Similarly, the absence of a human counterpart imposes an electronic selfservice performance by the client, prompting the manager to avail the latter with an electronic interface enabling a smooth service delivery without a human guide. To do this, the electronic interface should be, at the same time, ergonomic, with adapted contents, featuring a userfriendly design and taking into account different levels of familiarity of customers with computers. Note at this level, that the service provider is advised that the major contribution of the client in electronic service delivery should not be perceived negatively (eg, feeling like doing the work instead of the provider) and goes through it in a rather subtle way, which requires some "know-how" of the provider in the presentation and formulation of the servuction process.

In another aspect, the Internet client usually experiences a state of immersion where the service provider has the responsibility to endow this experience with a more or less pleasant feature. Indeed, the latter should bank on the attractiveness and user-friendliness of the website design, the wealth of features and links on the site and the efficient use of interactive computer tools in this respect. Thus, the optimization of the pleasant aspect felt by the Internet client could be a distinct advantage of the provider's website compared to those of competitors. Such is the case, also, of the "virtual community" function that the manager should offer on their service site to differentiate them, on the one hand, and to give customers the possibility of recovering the benefits of the social dimension including checking the opinions and experience feedbacks of other customers even in a virtual context, on the other hand. 
Furthermore, the transition from a traditional service experience to another on the service website requires the service manager to transpose the traditional atmosphere of the retail space onto a virtual environment which involves a work of "translation" of actual and tangible characteristics into virtual and digital ones. The difficulty for the manager is that of creating the atmosphere of virtual retail space through highlighting its rich presentation using only the formal features of the service website. This task is somehow rather complicated as it should enable him to trace back the same style and features of the traditional retail space (the graphics, color ...) to maintain a sense of familiarity with the customer. To do this, the manager has a fairly limited scope compared to that available to him in physical space. Thus, he should operate a variety of tools - including website design and graphic style used (colors, images, graphics, animation, video, music ...) combining them intelligently to achieve the desired effect, close to that of the reference in the most efficient and consistent way possible.

The managerial implications of the analysis stated in this article relate to a second component on the formation of the service brand image. At this level, we base ourselves on empirical results verifying that the direct experience of service greatly influences the service brand image that the client built in his/her mind (Camelis and Llosa, 2009). Consequently, any modification of service experience results in a change in the brand image associated with it. This observation is placed at the center of the analysis in this article. Indeed, following the passage from the context of traditional supply to that of the electronic one the service experience is altered in its content and its nature, which implies a change in the service brand image. For the manager, this change in context could go against the formation of the desired image if inconsistencies or "fracture" between the experience in real life and the one lived within the virtual framework occur. The challenge for the manager, thus, lies in knowing how to direct the electronic service experience that he offers to the desired brand image while not losing sight of the objective of coherence between the two experiences (that in the traditional and virtual context). And it is at this very level that our analysis is especially useful in practice for it is up to the manager to understand the implications of his decision to integrate an electronic form of the service on the experience that follows in order to orient it in the direction of the brand image he wishes to retrieve in his customers' minds. The fact that the brand image is already present - even partially in the mind of the customer in a traditional context only complicates the managerial work. Henceforth, the risk for the manager is that of associating to a new service experience a brand image that is inconsistent with that already formed in the client's mind and thus cause a "divide" between two images which should, in fact, form only one wich is harmoniously reflected in two different offering contexts. In an electronic environment, the manager should monitor changes in experiential activities during his adaptation of traditional servuction system to that electronic without distorting the brand image of reference for the consumer by enabling him/her to find the same functional and symbolic values of the latter during each direct experience of electronic service.

\section{Conclusion}

The analytical work undertaken in this paper highlights the impact of media technology in the supply of service via a website on the experience lived by the customer. Indeed, the passage from a context of traditional offer to another electronic reaches in-depth the experiential intensity of service affecting each type of activity that makes up the content of the whole experience which involves a restructuring of this experiential content. Henceforth, the "virtualization" of the context of supply generates the degradation of a large part of experiential activities traditionally present. But this does not imply any deterioration of experiential intensity since, on the opposite side, other experiential aspects specific to the electronic context arise thus balancing 
the level of intensity provided in accordance with the servuction system implemented by the service provider.

The analysis carried out leads us to conclude that the studied impact arises in three different forms: The first is a form of partial or almost total cancellation of certain aspects of traditional experience. The second refers to the transposition of some experiential aspects on the electronic environment and is expressed, henceforth, by other aspects adapted to this context. And finally, new aspects specific to the electronic environment of the service offer can be tested. As a matter of fact, experiential activities such as the stimulation of the sensory systems and the exclusive mobilization of cognitive resources are partially damaged in an electronic environment. We can, elsewhere, speak of a nearly total cancellation when it comes to behavioral activities referring to the minor physical effort made by the customer.

On the other hand, some aspects of the traditional service experience as social interactions are maintained and expressed, in an electronic environment, by virtual communities whose role is to transpose the social dimension - generally a source of satisfaction - on the virtual environment to foster interaction between the clients primarily and secondarily between client and service provider, where necessary. This applies also to certain features reflecting the richness of presentation of the atmosphere of the traditional retail space that are represented by the formal features of the service website including the design and the graphic style. Furthermore, the emotional aspects in the context of electronic offer are essentially marked by an immersive state which can be tested by the customer only in this context. Such is the case also in the use of interactive computer tools - like price comparison functionality - for data processing at the expense of the consumer's purely cognitive resources; These aspects unique to the electronic environment are favored by features specific to the virtual world such as the absence of geographical constraints, the interactivity and the level of flexibility from which the cyber customer derives profit regarding his choice of hypertext links and interactive tools plentifully available in this virtual context.

The practical relevance of the analysis presented in this paper lies in the fact of granting to the insight of the "metamorphosis" undergone by the service experience a central place on the one hand, in the success of management of the service quality, particularly in terms of homogenization of the quality level perceived by the consumer, and on the other hand, in the formation of a solid and coherent brand image avoiding any discrepancy in space and time. In the end, the service experience associated with a decision to integrate an electronic servuction system can be, for the manager, an effective and unavoidable strategy in the optimization of the overall quality of service perceived by the customer and in the consolidation of a positive and homogeneous brand image under the prerequisite of understanding and mastering the implications of such a decision on the content of the customer experience. The latter, besides its impact on the management of quality and brand, can be studied in a relational perspective where it certainly helps to strengthen the relationship between the consumer and the service provider, particularly in the development of the consumer's trust and commitment to the specific field of electronic supply service.

\section{References}

Ariely, D. (2000). "Controlling the Information Flow: Effects on Consumer Decision Making and Preferences," Journal of Consumer Research, 27, 2, 233-248.

Barnes, S. J. \& Vidgen, R. T. (2002). “An Integrative Approach to the Assessment of E-Commerce Quality," Journal of Electronic Commerce Research, 3, 3, 114-127.

Berry, L. L. (2000). "Cultivating Service Brand Equity," Journal of the Academy of Marketing Science, 28, 128-137. 
Bouchet, P. (2004). "L'expérience au Coeur de L'analyse des Relations MagasinMagasineur," Revue Française $d u$ Marketing, 19, 2, 1-19.

Bressolles, G. (2006). "La Qualité de Service Electronique: NetQu@1 Proposition d'une Echelle de Mesure Appliquée aux Sites Marchands et Effets Modérateurs," Recherches et Applications en Marketing, 21, 3, 19-45.

Bressolles, G. \& Durrieu, F. (2006). 'Une Typologie Prédictive de La Satisfaction En Ligne par La Qualité de Service Electronique,' Actes du 22ème Congrès International de L'association Française du Marketing, Nantes.

Camélis, C. \& Llosa, S. (2009). "Expérience de Service et Image de Marque: Implications Managériales," Congrès de L'association Française du Marketing. Londres 2009.

Eiglier, P. \& Langeard, E. (1987). 'Servuction: Le Marketing des Services,' Stratégie et Management, Paris, Mc GrawHill.

Fornerino, M., Helme-Guizon, A. \& De Gaudemaris, C. (2005). "L'immersion dans une Expérience de Consommation: Vers une Echelle de Mesure," 10èmes Journées de Recherche en Marketing de Bourgogne, Dijon, 9 - 10 Novembre, 42-57.

Fornerino, M., Helme-Guizon, A. \& Gotteland, D. (2006). "Mesure de L'immersion dans une Expérience de Consommation: Premiers Développements," Actes du XXII Eme Colloque International de l'Association Française du Marketing. Nantes, 11 Et 12 Mai.

Fornerino, M., Helme-Guizon, A. \& Gotteland, D. (2008). "Expériences Cinématographiques en Etat d'immersion: Effets sur La Satisfaction," Recherche et Applications En Marketing, 23, 3, 93-111.

Gurviez, P. \& De Montety, C. (2001). 'Le Contrat de Communication Fournisseur d'accès-Internautes: Une Recherche
Préparatoire,' Recherche et Applications En Marketing, 16, 3, 55-78.

Helme-Guizon, A. (2001). "Le Comportement du Consommateur sur un Site Marchand Est-il Fondamentalement Différent en Magasin ?, Proposition d'un Cadre d'appréhension de Ses Spécificités," Recherche et Application en Marketing, 16, 3, 25-38.

Hoffman, D. L. \& Novak, T. P. (1996). "Marketing in Hypermedia Computer Mediated Environments: Conceptual Foundations," Journal of Marketing, 60, 3, 64-77.

Holbrook, M. B. \& Hirschman, E. C. (1982). "The Experiential Aspects of Consumptions: Consumer Fantasies, Feelings and Fun," Journal of Consumer Research, 9, 2, 132-140.

Le Nagard-Assayag, E. (2000). 'Autour de La Notion d'interactivité: Vers Différents Médias Electroniques,' Revue Française du Marketing, 177, 29-47.

Parasuraman, A., Zeithaml, V. A. \& Malhotra, A. (2005). "E-S-QUAL: A MultipleItem Scale for Assessing Electronic Service Quality," Journal of Service Research, 7, 3, 213-233.

Philippe, J. (1994). 'La Qualité dans Les Rencontres de Service en Présence de L'ordinateur,' Actes Du 2ème Séminaire de Recherche en Management des Activités de Service, IAE d'Aix En Provence.

Rayport, J. F. \& Sviokla, J. J. (1995). "Exploiting the Virtual Value Chain," Harvard Business Review, November/December 1995.

Rolland, S. (2005). 'Impact de L'utilisation de Sites Web sur La Qualité Perçue en Magasin,' Congrès de L'association Française du Marketing. Nancy 2005.

Sabadie, W. (2001). Contribution a La Mesure de La Qualité Perçue d'un Service Public, Thèse de Sciences de Gestion, Université des Sciences Sociales de Toulouse, Décembre 2001. 
Sabadie, W. \& Vernette, E. (2003). "La Servuction on Line: Points Communs et Spécificités Face a La Servuction Traditionnelle," Actes de La 2ème Journée AFM sur Le E-Marketing, Nantes.

Steuer, J. (1992). "Defining Virtual Reality: Dimensions Determining Telepresence," Journal of Communication, 42, 4, 73-93.

Tournois, N. (1999). 'Le Marketing Bancaire Face aux Nouvelles Technologies,' Paris, Masson.

Volle, P. (2000). 'Du Marketing des Points de Vente a Celui des Sites Marchands: Spécificités, Opportunités et Questions de Recherche,' Revue Française du Marketing, 177-178, 2-3, 83-101.

Wolfinbarger, M. \& Gilly, M. C. (2003). 'Shopping Online for Freedom, Control, and Fun,' California Management Review, 43, 2, 34-55. 